\title{
A Giant Ovarian Tumour (7.5kg) During Pregnancy with its Successful Perinatal and Surgical Outcome
}

\author{
Katke RD ${ }^{*}$ \\ Department of Obstetrics and Gynaecology, Medical Superintendent of Cama and Albless Hospital, Mumbai, India
}

*Corresponding author: Katke RD, Department of Obstetrics and Gynaecology, Medical Superintendent of Cama and Albless Hospital, Mumbai, India, Tel: 9869917830 Email: drrajshrikatke@gmail.com

Citation: Katke RD (2017) A Giant Ovarian Tumour (7.5kg) During Pregnancy with its Successful Perinatal and Surgical Outcome. SAJ Case Reports 4: 104

Article history: Received: 07 January 2017, Accepted: 31 January 2017, Published: 26 February 2017

\begin{abstract}
Here we are reporting an unusual case of a large ovarian tumour during pregnancy. A 26 years female with 8 months of amenorrhea presented with chief complaint of pain in abdomen and an ultrasonography suggestive of single live intrauterine gestation of 29 weeks with large left ovarian cystic lesion of size 16.2 × $9.6 \mathrm{~cm}$ extending up to epigastrium. Magnetic resonance imaging of abdomen and pelvis was done suggestive of a large ovarian mass arising from left ovary of $10.5 \times 21 \times 24 \mathrm{~cm}$ size with well-defined peripherally enhancing multilobulated multi cystic lesion with multiple septations with in. CA 125 and CEA levels were within normal range. Patient delivered a male baby vaginally. Repeat CA 125 and CEA levels and MRI [Abdomen+Pelvis] was done in post-partum period and was within normal range. Exploratory laparotomy with left ovarian mass excision done. Histopathological report was suggestive of benign mucinous cystadenoma.
\end{abstract}

Keywords: Benign Mucinous Cystadenoma; Large Ovarian Tumour during Pregnancy

\section{Introduction}

Ovarian Cyst is a sac like structure lined by epithelium and filled with fluid, may contain water like fluid, blood etc. It can be benign, malignant or borderline. Incidence of benign ovarian cyst is more common and occurs in $0.5-3 \%$ pregnancies. Benign ovarian cysts include - follicular cyst and luteal cyst. If associated with pregnancy most of them are smaller in size but may be larger and may be asymptomatic or symptomatic [1]. Incidence of ovarian masses increases in pregnancy with increasing age. With the help of newer imaging technologies early detection on any ovarian mass is possible. Ultrasonography scanning can detect an adnexal mass in 1 in 200 early pregnancies. Clinically detectable adnexal masses are found in 1 in 1500 pregnancies. A cyst may remain of same size or may continue to grow for few weeks to a few months without any symptoms but may also present with following symptoms pain in abdomen, bloating or mass per abdomen, pressure on bowel or bladder, bowel discomfort, constipation etc. Its management depends on size, symptoms and duration of pregnancy. Some may resolve spontaneously during course of pregnancy whereas some may need surgical intervention. The treatment of an ovarian cyst completely depends on the nature of mass - benign or malignant. If the cyst continues to grow or if it is causing severe pain, then surgery is needed to remove it. Any operation to remove the cyst will be done only after 20 weeks of pregnancy. A surgery to remove the cyst during early pregnancy may increase the risk of miscarriage which is usually done in cases of complications like tortion, rupture or hemorrhage of cyst.

\section{Case Report}

A 26 years female G4P3L3 with previous all normal vaginal deliveries with 8 months of amenorrhea presented with complaint of pain in abdomen and an Ultrasonography report suggestive of single live intrauterine gestation of 29 weeks with a large left ovarian mass of size 16.2 x $9.6 \mathrm{~cm}$ extending up to epigastrium. On examination patient was vitally stable. Per abdomen examination had uterus of 30- 32 weeks, fetal heart rate was $140 \mathrm{bpm}$, regular and relaxed and a firm mass of $16 \mathrm{x} 10 \mathrm{~cm}$ palpable on left side of abdomen, separate from uterus. Per speculum examination had no leaking or bleeding. On per vaginal examination cervical os was parous deviated more on left side. Urgent ultrasonography [obstetrics +abdomen+pelvis] with colour Doppler of mass done to rule out ovarian cyst tortion. It was suggestive of single live intrauterine gestation of 30 weeks with left ovarian cystic mass of $17.4 \times 10.8 \mathrm{~cm}$ with normal colour Doppler study of the mass. All routine investigation done and found with in normal range. CA $1258.37 \mathrm{IU} / \mathrm{ml}$ ( normal range - < 35IU/ML) and CEA 3.53 ( normal range- 0-2.5Microgm/l) levels were within normal 
range. MRI was done suggestive of large left ovarian complex cyst of $10.5 \times 21 \times 24 \mathrm{~cm}$ with well-defined peripherally enhancing multilobulated multi cystic lesion with multiple septations. Patient delivered a male baby vaginally with no complications. Postdelivery repeat all routine investigation and CA 125 and CEA levels were done. They were within normal range. Post-delivery MRI $[\mathrm{A}+\mathrm{P}]$ done was suggestive of same findings as in previous report. Exploratory laparotomy with left ovarian mass excision done after perpeural period was over and patient was stable. Intra-operative findings showed a large cystic mass of $30 \times 25 \times 15 \mathrm{~cm}$ size arising from left ovary with multiple dilated vessels present over mass [Figure 1,2 and 3]. Left ovarian cystic mass weighed $7.5 \mathrm{~kg}$ after removal. Tumour mass was sent for Histopathological report [Figure 4]. Histopathological report was suggestive of benign mucinous cystadenoma. Patient withstood procedure well. Patient course in ward uneventful and discharged after suture removal.

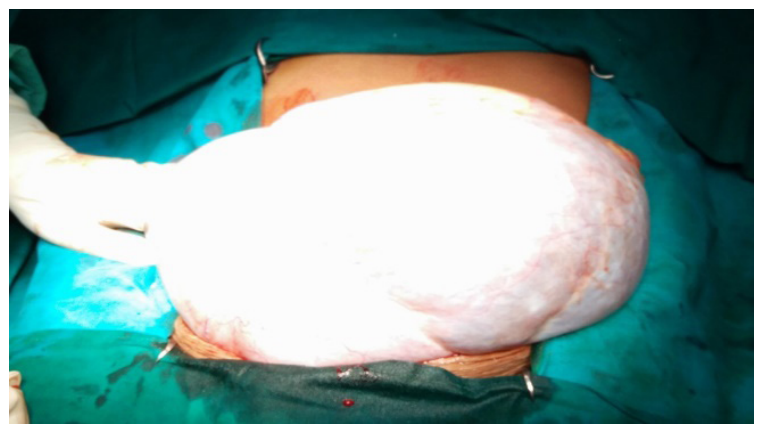

Figure 1: Intra-operative findings large cystic mass of $30 \times 25 \times 15 \mathrm{~cm}$ size arising from left ovary, multiple dilated vessels present over mass.

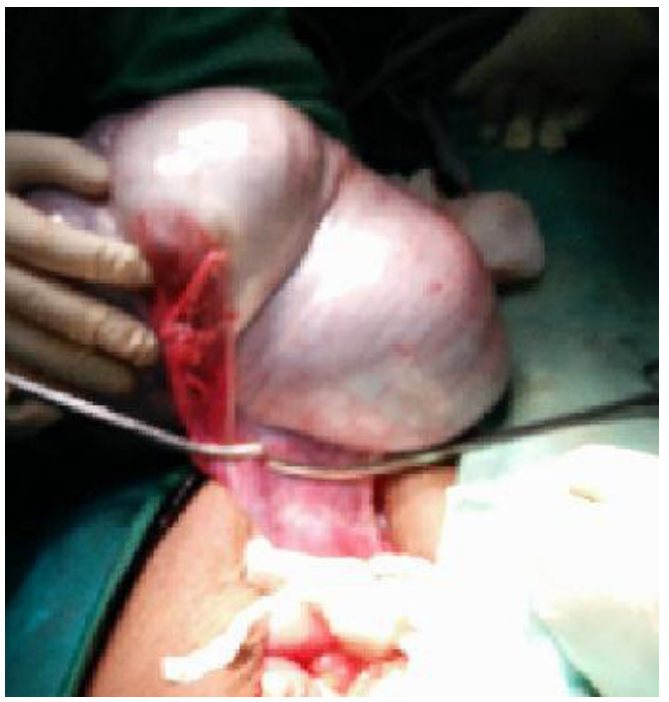

Figure 2: Intra-operative picture of large left sided ovarian mass.

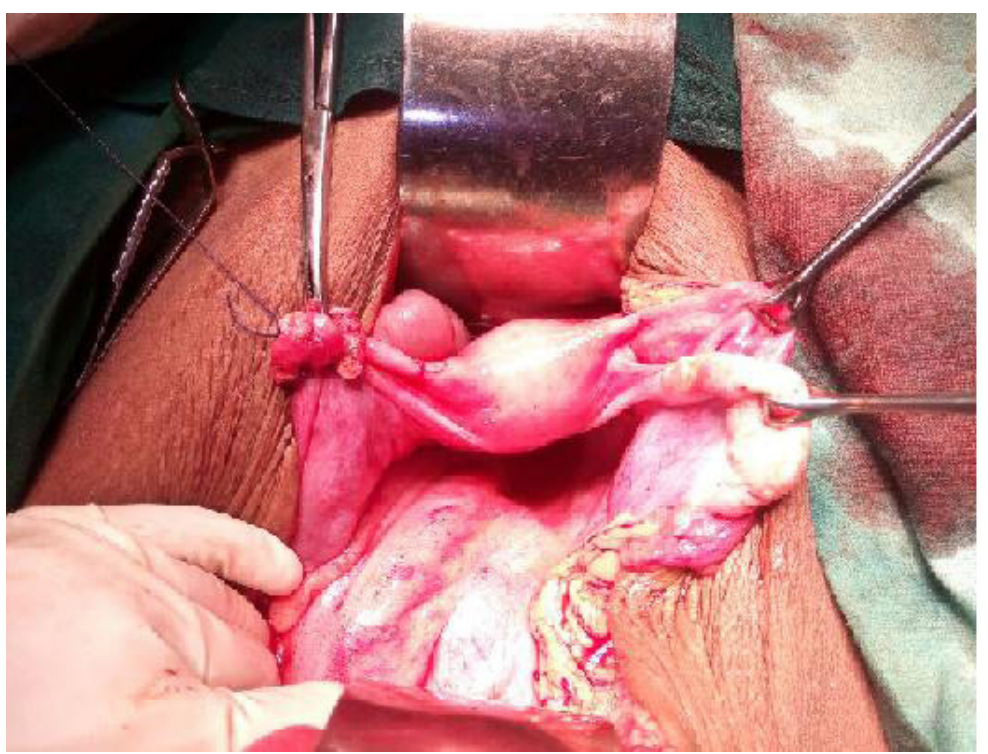

Figure 3: Intraoperative picture with preserved uterus and right side ovary 


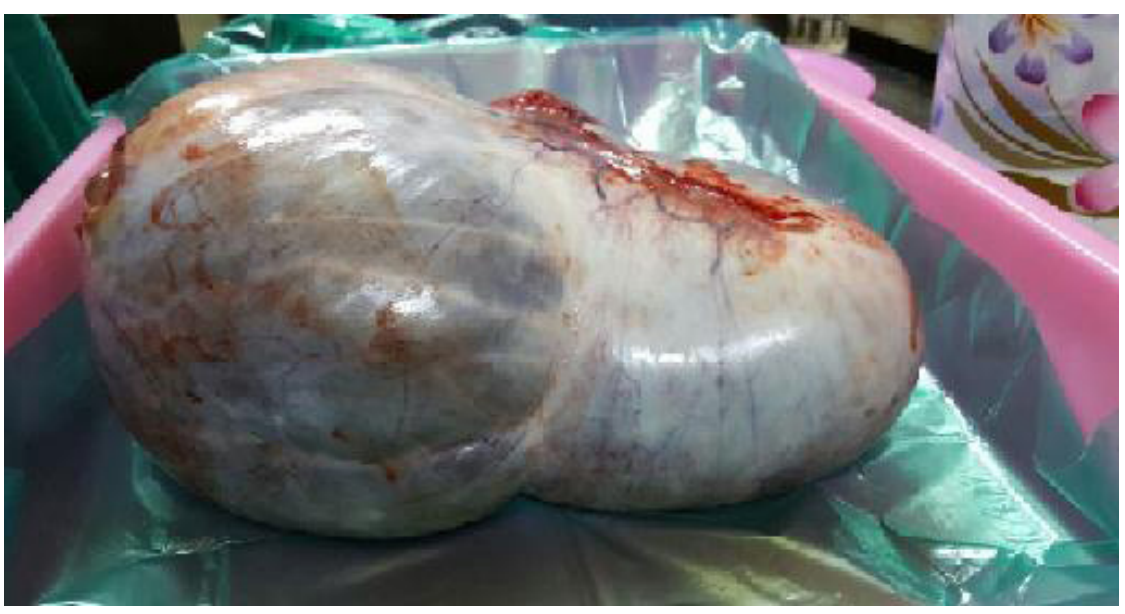

Figure 4: A huge ovarian mass of $7.5 \mathrm{kgs}$

\section{Discussion}

The most frequent type of ovarian tumours seen in pregnancy are - serous cystadenoma, corpus luteal cysts, endometriomas and mature cystic teratoma. Mucinous cystadenomas are thin walled, translucent cysts usually multilocular, varying between 20-30 $\mathrm{cms}$ in size. Although benign ovarian mucinous tumours are rare at the extremes of age, before puberty and after menopause [2], they are common between the third and the fifth decades [3]. It is reported to occur more commonly in middle-aged women. It is rare among adolescents [4] or in association with pregnancy [5]. On gross appearance, mucinous tumours are characterized by cysts of variable sizes without surface invasion. They are often unilateral but can be bilateral [6]. Most of them are nonmalignant, $10-15 \%$ of them are borderline malignant while 20-40\% are malignant [7]. Yenicesu GI et al and Qublan HS et al both described removal of right ovarian mucinous cystadenomas weighing around $6 \mathrm{~kg}$ after Caesarean section. The cysts in both cases were very similar to that in our patient. In our case, however, the baby was delivered vaginally without any intra partum and postpartum complications despite the presence of such a huge ovarian mass. This is indeed a rare case because there have been no reports in the existing literature on vaginal delivery complicated by such a huge ovarian mucinous cystadenoma. Complications of the ovarian cysts associated with pregnancy are torsion of the cyst, rupture, infection, malignancy, intrauterine growth restriction, preterm labour, obstructed labour and mal presentations of the fetus [1]. Ovarian torsion occurs most frequently in the first trimester, occasionally in the second, and rarely in the third trimester. Most ovarian masses can either remain asymptomatic but in our case patient complaints of chronic pain in abdomen which was not associated with any torsion and do not hamper in pregnancy outcome and thus the incidence of the above risks are actually low. Most common cause of ovarian cyst in pregnancy is a corpus luteum cyst, which usually regresses spontaneously by the second trimester without need of any surgical intervention. The great majority of high suspicion adnexal masses excised during pregnancy are in fact borderline ovarian tumors [8]. According to some authors resection of all suspected cysts at risk of rupture or undergoing torsion is recommended. Cysts measuring $10 \mathrm{~cm}$ in diameter should be resected due to increased risk of cancer in the large cysts, while cysts less than $5 \mathrm{~cm}$ could be left alone, and indeed, most undergo spontaneous resolution. Management of cysts between 5 and $10 \mathrm{~cm}$ in diameter remains controversial. Some clinicians recommend that these cysts be managed expectantly if they have cystic appearance. Others believe that if they contain septae, nodules, papillary excrescences, or solid component, resection is recommended [9]. According to study done by Lille's in France a simple monitoring is possible if the cyst is benign, less than $6 \mathrm{~cm}$ and does not change. Surgery is required in an emergency or in case of suspicious signs of complications or malignancy. Laparoscopy can be widely used until the 2nd quarter.

\section{Conclusion}

In our case the patient was admitted at 8 months of gestation with large left sided ovarian mass. Exploratory laparotomy with excision of left ovarian cyst was done after normal vaginal delivery after postpartum period and hence gives successful both fetomaternal outcome. Ovarian cyst in pregnancy must be followed up carefully as the prognosis is unpredictable. A cystic lesion with benign appearance with size $<5 \mathrm{~cm}$ generally does not need any surgical intervention. Cysts of size $5 \mathrm{~cm}$ to $10 \mathrm{~cm}$ require careful evaluation and monitoring with serial sonography and MRI, and should be taken for surgical resection if cyst grows,becomes symptomatic and any malignant changes occurs.

\section{References}

1. Qublan HS, Al-Ghoweri AS, Al-Kaisi NS, AbuKhait SA (2002) Benign mucinous cystadenoma with stromal luteinization during pregnancy: a hormonally responsive tumor and a rare cause of fetal intrauterine growth restriction. J Obstet Gynaecol Res 28: 104-7.

2. Yenicesu GI, Cetin M, Arici S (2015) A large ovarian mucinous cystadenoma complicating pregnancy Bali Medical Journal (Bali Med J) 4.

3. Turgrul S, Pekin O, Ayvaci H Tarhan N, Uludogar M (2007) Giant benign mucinous cystadenoma growing during pregnancy: a case report. Clin Exp Obstet Gynecol 34: 1267.

4. Ioffe OB, Simsir A, Silverberg SG (2000) In: Practical Gynaecologic Oncology. Berek JS, Hacker NF, editor. Lippincott Williams \& Wilkins Company Pathology 213-4. 
5. Ozgun MT, Turkyilmaz C (2009) A giant ovarian mucinous cystadenoma in an adolescent: a case report. Arch Med Sci 5: 281-3.

6. Yenicesu GI, Cetin M, Arici S (2009) A huge ovarian mucinous cystadenoma complicating pregnancy: a case report. Cumhuriyet Med J 31: 174-7.

7. Katke RD (2015) Huge Mucinous Cystadenoma of ovary: CaseReport with Review of Literature. International journal of reproduction contraceptive obstetrics. gynecol 3.

8. Katke RD Successful Outcome of Pregnancy in Borderline Malignant Ovarian Tumor. JCR 4: 391-4.

9. Fleischer al, Dimesh Ms, Entman Ss (1990) Sonograhic evaluation of maternal disorders during pregnancy. Radiol Clin North Am 28:51. 